\title{
The Application of Psychological Consultation for College Counselors in the New Situation
}

\author{
Qing Chen ${ }^{1,}$, Pengming Wang ${ }^{2, b}$ \\ ${ }^{1}$ School of Science Subjects, East China Jiaotong University, Nanchang 330013, China \\ ${ }^{2}$ School of Information Engineering, East China Jiaotong University, Nanchang 330013, China \\ a80925699@qq.com, bzhangwuji115@163.com
}

\begin{abstract}
The theory and technology of psychological consultation are well consistent with the law of higher education and the physical and mental development of college student, which can be widely used in the education, management and service work of counselors. In this paper, we combine the technology of psychological consultation with the practical work of counselors, induce and explain how the specific techniques of psychological consultation can applied into the students' educational work, so as to improve the effectiveness of ideological and political education, adapt the work of counselors to the changing environment, and promote the comprehensive development of students truly.
\end{abstract}

Keywords: counselor; psychological consultation; service for student; communication.

\section{新形势下高校辅导员学生心理咨询技术的运用}

\author{
陈青 ${ }^{1}$, 王鹏鸣 ${ }^{2}$ \\ 1华东交通大学理学院, 南昌 中国 \\ 2华东交通大学信息工程学院, 南昌 中国
}

摘 要: 心理咨询的理论和技术符合高等教育规律和大学生身心发展规律, 可以广泛运用于辅 导员的教育、管理和服务工作中, 本文将心理咨询技术和辅导员实际工作相结合, 归纳和阐述 如何将心理咨询的具体技术运用到学生教育工作中, 从而提高辅导员思想政治教育的有效性, 以使辅导员工作更能适应不断变化的历史环境, 真正实现促进学生全面发展。

关键词: 辅导员; 心理咨询; 学生服务; 师生交流.

\section{1. 心理咨询在辅导员工作中的重要价值}

教育部颁布的《普通高等学校辅导员队伍建设规定》中明确提出 “辅导员是高等学校教师队 伍和管理队伍的重要组成部分, 具有教师和干部的双重身份。辅导员是开展大学生思想政治教 育的骨干力量, 是高校学生日常思想政治教育和管理工作的组织者、实施者和指导者。辅导员 应当努力成为学生的人生导师和健康成长的知心朋友 ${ }^{[1]}$ 。” 辅导员在学生的思想政治教育工 作中起到举足轻重的作用, 但是我们传统的辅导员工作常常忽略了学生个体的差异和学生的 接受能力以及学生的认同度, 重管理, 轻教育, 教育、管理的方式简单、缺乏科学性, 只是简单 的以制度和纪律来管理和约束大学生, 忽视了大学生的发展需求, 忽视了大学生的主体性, 忽 视了大学生的心理差异, 难以引起学生的共鸣得到学生的认同, 导致教育、管理的效果不够理 想。

2002 年教育部颁布《普通高等学校大学生心理健康工作实施纲要》明确指出 “大学生心理教 育是高等学校德育教育工作的重要组成部分, 而德育与思想政治教育在实践中并没有明确的 分界线, 而心理咨询工作是心理健康教育实施的主要途径, 它与心理健康教育是密不可分的 [1]”。这就把心理咨询作为高校思想政治教育的一个重要途径, 加以明确。心理咨询最核心的 
观点就是以来访者为中心, 把解决来访者的问题和帮助来访者发展作为主要工作目标, 而这一 点恰恰是我们传统的辅导员工作中所缺乏的。传统的辅导员工作往往注重学生面上的教育和 管理, 而忽视了学生个体的差异和发展需要, 使工作浮于表面, 无法深入学生内心, 导致学生的 认同感不强。

辅导员工作应该把国家的方针政策、学校的人才培养目标和学生的实际情况相结合, 在实际工 作中既要重视学生的群体特殊又不能忽视学生的个体差异, 针对不同年龄段学生的生理、心理 差异适时调整工作方式和方法, 找到最切合学生实际, 最能被学生认同的教育、管理、服务模 式。只有认真学习心理学相关理论, 才能掌握大学生的心理特点, 将心理咨询的理论与方法与 辅导员的具体工作实际相结合, 才能探索出新时期辅导员工作的新模式。

\section{2. 心理咨询技术在辅导员实际工作中的运用}

高校思想政治教育、品德人格的培养都是顺利实施管理工作的前提; 而严格有效的管理又是思 想政治教育、品德人格培养的有力保障; 而不管是思想政治教育、品德人格培养、还是严格有 效的教育最终都是为学生成人成才服务。“高校进行思想政治教育, 不是为了教育而教育, 而 是为了用正确的理论指导行动。如果人们的思想出现问题, 其行为必然会出现偏差 ${ }^{[2]}$ 。” 针对 大学生的心理特点和常见的心理问题, 作为辅导员要将心理咨询的技术和方法引入思想政治 教育中, 充分发挥心理咨询的功能, 这样既能增强思想政治教育方法的科学性, 又能增强思想 政治教育的实效性。

2. 1. 运用尊重技术, 平等对待学生, 为思想政治教育搭建人性化平台 心理咨询技术中所谓的尊重强调的是咨询师对来访者无条件的接纳。而我们辅导员在实际工 作中会以自己的价值观来评价学生, 以自己的喜好来区别对待学生, 而运用尊重的技术就是要 求辅导员在面对学生个体时要完全的接纳学生的一切, 以平等的眼光来看待学生, 而不能有老 师高高在上的权威意识和家长意识, 要主动参与到学生的学习、生活各个环节, 与学生平等交 流和相处。特别是当学生的思想行为出现问题时不能简单的批评, 说教, 而必须从内心尊重学 生的价值、尊严和人格, 以平等的心态来帮助学生分析原因, 找出解决问题的办法, 只有在教育 过程中真正的从学生出发, 才能为思想政治教育搭建人性化的平台, 才能使思想政治教育入脑 入心。

2. 2. 运用倾听技术, 了解学生实际, 为思想政治教育奠定信息基础 心理咨询技术中的倾听是建立良好咨询关系的基本要求, 它体现了咨询者对来访者的一种尊 重, 是心理咨询的第一步, 可以让来访者在宽松和信任的环境中与咨询者进行交流。而我们辅 导员在实际工作中往往都是扮演说教者的角色, 自己说得多, 教育得多, 不管是在公开场合面 对学生群体还是在私底下与学生交流, 只要学生一旦提出问题, 辅导员就会以很多的道理对学 生进行灌输式教育, 很多时候感觉苦口婆心, 而不被学生理解和接受, 有时还会导致学生产生 抵触情绪, 使思想政治教育陷入僵局。而心理咨询的倾听技术正是要求辅导员要认真、耐心地 听学生的倾诉, 转变以前说教者的身份而成为一个受欢迎的倾听者, 在倾听中了解学生的所思 所想, 了解学生的困惑和需求, 了解问题发生的原因, 帮助学生理清不良情绪产生的原因, 问题 行为出现的症结, 便于正确收集信息, 做出正确的判断和处理, 适时调整思想政治教育的内容 和方法。这种倾听也是辅导员对学生尊重的一种体现, 这种尊重能够更快的得到学生的认同, 使思想政治教育更能切合学生实际, 符合学生需求。

\section{3. 运用真诚技术, 走进学生内心, 为思想政治教育奠定信任基础}

心理咨询技术中的 “真诚” 也是良好咨询关系建立的一个重要因素, 要求咨询师必须在整个咨 询过程中能够真挚诚恳的对待来访者, 不掩饰, 不回避, 不取悦。而运用到辅导员工作实际中就 是要真诚的与学生相处和交流, 有些辅导员在工作开展中为了树立自己的权威或者树立自身 的完美形象, 与学生交往很少, 不主动参与学生的学习和生活环节; 或者与学生交流的时候讲 的是一套理论, 而自己在实际生活和工作中又是另一套做法; 或者在与学生的交流和相处中总 是爱讲大道理, 而且由于受自己本身学识的局限, 总是老生常谈。这些都容易让学生觉得辅导 
员为人不真诚, 交流和相处起来不能真诚的投入信任, 也会为辅导员的思想政治教育造成一定 的阻力。辅导员在与学生相处的每一个环节都必须以真诚的心态, 坦诚的态度来对待, 人无完 人, 辅导员要真诚的接纳学生的不完美甚至小错误, 也不要惧怕让学生看到辅导员自身的不足, 只有让学生觉得辅导员也是一个有血有肉的人, 也是在自己的人生道路上通过自身的努力不 断进步着的独立个体, 学生才会了解辅导员、理解辅导员, 从而达成相互信任, 相互理解, 彼此 支持, 共同成长。

2.4. 运用共情技术, 建立良好信任, 为思想政治教育奠定情感基础

共情主要指能够设身处地的站在当事人的角度去理解当事人的情感、思维, 并将这种理解传递 给当事人。共情的好处就是可以让对方感觉自己被理解, 被悦纳, 从而产生愉悦的情绪。而在 实际工作中, 辅导员通常都是站在自己的立场, 更多的是为了完工作要求而简单的开展工作, 只求能够应对各种要求, 各种检查, 而忽视了大学生真正的内心需要、思想需求、情感需求。 特别是当学生的思想出现问题导致问题行为的发生时, 辅导员通常都会用校纪校规去约束和 惩戒学生, 而实际上当学生出现问题行为时是辅导员更应该关心学生的时候, 认真倾听学生的 想法, 设身处地站在学生的角度去想问题, 才能更多的了解学生真实的心声, 帮助学生找到问 题出现的真正原因, 从而达到教育、影响的目的。学生也会因为辅导员的理解而打开心灵的大 门, 建立真诚的情感, 为思想政治教育建立良好的情感基础, 营建和谐的情感氛围。

2. 5. 运用关注技术, 培养学生自信, 为思想政治教育奠定动力基础

心理咨询技术中的关注, 是指对来访者的言语和行为的积极面予以关注, 从而使来访者拥有正 向价值观。其实, 每个人都有自己的长处和优点, 都拥有积极向上的动力, 通过自己和外界的帮 助, 都能获得成长和进步。处在青年期的大学生, 他们缺乏正确客观的社会认知, 人生观、世界 观和价值观还没有完全形成, 随着社会的发展, 受外界的各种影响, 大学生难免会出现思想上 的迷焵、情感上的冲击而导致心理上的各种冲突, 他们渴望被人关注, 被人认同, 特别是那些自 卑感强或者因面临挫折和困难而不能正确认识自己的学生, 尤其渴望被人关注和理解, 如果辅 导员能够积极的关注他们, 和他们多交流, 多相处, 对他们的优点和长处给予正面的肯定, 他们 就能更快的走出成长困境, 树立信心, 从而实现成长。正如马克思所讲 “人来到世界, 既没有带 镜子, 也不像哲学家那样, 说什么 “我就是我”, 所以人总是通过别人来反映自己 ${ }^{[3]}$ 。” 因此, 对学生的关注是辅导员开展思想政治教育的前提, 只有积极认真的关注才能真正的了解自己 的学生, 熟悉他们的情况, 急学生之急, 想学生所想, 这样也才能使思想政治教育, 言之有物, 言 之有理, 易于被学生接受, 达到润物细无声的目的。

2. 6. 运用团体心理咨询技术, 培养学生自我反省意识, 为思想政治教育奠定意识基础 团体心理咨询是从英文group counseling翻译而来的。我国清华大学心理学教授栎富瑕将团 体辅导定义为 “在团体情境中提供心理咨询与指导。它是通过团体内人际交互作用, 促使个体 在交往中通过观察、学习、体验, 认识自我、探讨自我、接纳自我, 调整和改善与他人的关系, 学习新的态度与行为方式, 以发展良好的生活适应的助人过程。它不仅是一种有效的心理辅导 方式, 也是一种创新的集体教育活动 ${ }^{[4]}$ ”。因为是以小组的形式进行, 所以效率高, 省时省力, 同时感染力强, 影响广泛, 而且效果容易巩固。是辅导员思想政治教育活动中值得借鉴的好方 法。

心理咨询技术在思想政治教育过程的运用, 弥补了传统教育方法的缺陷, 使辅导员能更多的了 解学生的认识、情感、意志和态度, 从而总结和掌握大学生的思想活动规律。而大学生的思想 活动规律又是受制于心理活动规律的, 因此, 高校思想政治教育要取得理想的效果, 就必须符 合大学生的心理活动规律。所以辅导员在思想政治教育过程中必须掌握一定的心理咨询原则 和方法, 特别是心理咨询的实用技术, 并行之有效的运用在工作实际中, 才能使思想政治教育 入脑入心, 不断走向科学化。 


\section{3. 结束语}

本文以结合工作实际, 详细阐述了心理咨询的具体技术在思想政治教育工作中的运动, 比较透 彻的论证了心理咨询与辅导员工作密不可分, 心理咨询技术在辅导员工作中的重要价值, 心理 咨询技术能够提高辅导员思想政治教育的有效性、针对性、专业性。能够推进辅导员工作的 科学化和规范化, 切实提高辅导员的工作水平, 促进我国思想政治教育的进一步发展。

\section{致谢}

基金项目：华东交通大学校立课题（14LX05）

\section{References}

[1]. Li Zhang. The Orientation of College Counselor Role [J]. Journal of Chang Jiang University (Social Science Edition), (2008) No.6, p. 142.

[2]. The Education Ministry of the People's Republic of China. The regulations for the construction of college counselor team in Colleges and Universities. 2006.7, No. 24.

[3]. Complete Works of Marx and Engels. People Press, 1995. 2(23), p. 67.

[4].Fuxia Fan. The Theory and Practice of Group Counseling [M]. Tsinghua University Press, 1996.1, p. 2. 